\title{
In-Situ Investigation of Gas Phase Radical Chemistry in the Catalytic Partial Oxidation of Methane on Pt
}

\author{
M. Geske, K. Pelzer, R. Horn, F.C. Jentoft, R. Schlög1*
}

Fritz Haber Institute of the Max Planck Society, Department of Inorganic Chemistry, Faradayweg 4-6, 14195 Berlin, Germany

\begin{abstract}
Available online 28 February 2009

The catalytic partial oxidation of methane on platinum was studied in situ under atmospheric pressure and temperatures between 1000 and 1300 ${ }^{\circ} \mathrm{C}$. By combining radical measurements using a molecular beam mass spectrometer and threshold ionization with GC, GC-MS and temperature profile measurements it was demonstrated that a homogeneous reaction pathway is opened at temperatures above $1100{ }^{\circ} \mathrm{C}$, in parallel to heterogeneous reactions which start already at $600{ }^{\circ} \mathrm{C}$. Before ignition of gas phase chemistry, only $\mathrm{CO}, \mathrm{H}_{2}, \mathrm{CO}_{2}$ and $\mathrm{H}_{2} \mathrm{O}$ are formed at the catalyst surface. Upon ignition of gas chemistry, $\mathrm{CH}_{3}$. radicals, $\mathrm{C} 2$ coupling products and traces of $\mathrm{C} 3$ and $\mathrm{C} 4$ hydrocarbons are observed. Because the formation of $\mathrm{CH}_{3}$. radicals correlates with the formation of $\mathrm{C} 2$ products it can be concluded that $\mathrm{C} 2$ products are formed by coupling of methyl radicals in the gas phase followed by dehydrogenation reactions. This formation pathway was predicted by numerical simulations and this work presents an experimental confirmation under high temperature atmospheric pressure conditions.
\end{abstract}

Keywords: catalytic partial oxidation, methane, platinum, methyl radical, molecular beam mass spectrometry, gas phase chemistry

\section{Introduction}

The presence of vast reserves of natural gas containing predominantly methane has encouraged scientific efforts to utilize it as chemical feedstock, alternatively to crude oil. Currently, research is directed to convert methane by catalytic partial oxidation (CPO) into i) synthesis gas (Eq. 1) [1], ii) ethylene (Eq. 2) [2], iii) formaldehyde (Eq. 3) [3] and iv) methanol (Eq. 4) [3]. Whereas methane CPO to formaldehyde and methanol is at the research stage and far from being commercially relevant (few \% yields), methane CPO to ethylene (oxidative coupling) yields up to industrially interesting $25 \% \mathrm{C} 2$ yield $\left(\mathrm{C}_{2} \mathrm{H}_{6}+\mathrm{C}_{2} \mathrm{H}_{4}+\right.$ $\mathrm{C}_{2} \mathrm{H}_{2}$ ) [4] and methane CPO to syngas has reached pilot plant stage [1].

$$
\begin{array}{ll}
\mathrm{CH}_{4}+\mathrm{t} / 2 \mathrm{O}_{2} \rightarrow \mathrm{CO}+2 \mathrm{H}_{2} & \Delta_{5} \mathrm{H}^{\circ}=-36 \mathrm{~kJ} / \mathrm{mol} \\
\mathrm{CH}_{4}+\mathrm{t} / 2 \mathrm{O}_{2} \rightarrow \mathrm{t} / 2 \mathrm{C}_{2} \mathrm{H}_{4}+\mathrm{H}_{2} \mathrm{O} & \Delta_{4} \mathrm{H}^{\circ}=-185 \mathrm{~kJ} / \mathrm{mol} \\
\mathrm{CH}_{4}+\mathrm{O}_{2} \rightarrow \mathrm{HCHO}+\mathrm{H}_{2} \mathrm{O} & \Delta_{5} \mathrm{H}^{\circ}=-320 \mathrm{~kJ} / \mathrm{mol} \\
\mathrm{CH}_{4}+\mathrm{t} / 2 \mathrm{O}_{2} \rightarrow \mathrm{CH}_{3} \mathrm{OH} & \Delta_{4} \mathrm{H}^{\circ}=-164 \mathrm{~kJ} / \mathrm{mol}
\end{array}
$$

The motivation of the present work was to investigate the impact of gas phase chemistry on the methane oxidation on Pt because there is evidence in the literature that gas phase reactions play an important role for the above mentioned target transformations. In particular the focus is on the oxidative coupling of $\mathrm{CH}_{4}$ to $\mathrm{C} 2$ species.

Catalytic methane oxidations and many other alkane oxidations are very exothermic and often very fast. In this situation heat generation is typically faster than heat losses by convection, conduction and radiation leading to high temperatures and interesting phenomena such as coupled surface-gas reactions, mass and heat transport limitations, ignition-extinction of surface chemistry, ignition-extinction of gas phase chemistry and autothermal reactor operation. Of particular interest is the exchange of radicals between the surface and the gas phase $[5,6]$. As will be outlined in the following scattered experimental and numerical studies exist shedding light onto different aspects of methane oxidation and methane coupling on Pt but it is an open question whether these results can be extrapolated to high temperature $\left(>1000^{\circ} \mathrm{C}\right)$ and high pressure $\left(>10^{5} \mathrm{~Pa}\right)$ conditions $[7,8]$. 
The surface chemistry of the methane oxidation on Pt has been studied extensively in the past and only the main results can be summarized here. Generally there is consent that $\mathrm{CO}, \mathrm{H}_{2}, \mathrm{CO}_{2}$ and $\mathrm{H}_{2} \mathrm{O}$ are the main surface reaction products with high selectivities to $\mathrm{CO}_{2}$ and $\mathrm{H}_{2} \mathrm{O}$ at low temperatures and to $\mathrm{CO}$ and $\mathrm{H}_{2}$ at high temperatures [9-12]. It is always observed that the selectivity to $\mathrm{H}_{2}$ increases more strongly with temperature than that of $\mathrm{CO}$. A recent study reporting spatially resolved concentration and temperature profiles in a $\mathrm{Pt}$ foam catalyst gives an explanation of these general trends by showing that the methane CPO is a combination of exothermic total and partial oxidation reactions and endothermic reforming reactions [12]. In presence of gas phase oxygen at the beginning of the catalyst bed the reaction can be described by the stoichiometric equation (Eq. 5) in which $\mathrm{x}(0 \leq \mathrm{x} \leq 2)$ and $\mathrm{y}(0 \leq \mathrm{y} \leq 1)$ depend on the partial pressure of the reactants and the temperature.

$$
\begin{aligned}
& \mathrm{CH}_{4}+(2-\mathrm{x} / 2-\mathrm{y} / 2) \mathrm{O}_{2} \\
& \rightarrow \mathrm{x} \mathrm{H}_{2}+\mathrm{y} \mathrm{CO}+(2-\mathrm{x}) \mathrm{H}_{2} \mathrm{O}+(1-\mathrm{y}) \mathrm{CO}_{2}
\end{aligned}
$$

At synthesis gas stoichiometry $(\mathrm{C} / \mathrm{O}=1.0)$ and high temperatures $\left(\mathrm{T}>1000{ }^{\circ} \mathrm{C}\right), \mathrm{x}$ and $\mathrm{y}$ are close to unity so that $\mathrm{H}_{2}, \mathrm{CO}$ and $\mathrm{H}_{2} \mathrm{O}$ are nearly formed in equimolar amounts whereas only small amounts of $\mathrm{CO}_{2}$ are formed. After gas phase oxygen has been consumed, methane conversion continues with water as co-reactant meaning that steam reforming (Eq. 6) is the dominant reaction path

$$
\mathrm{CH}_{4}+\mathrm{H}_{2} \mathrm{O} \rightarrow \mathrm{CO}+3 \mathrm{H}_{2}
$$

Whereas $\mathrm{CO}_{2}$ reforming seems to be negligible under high temperature conditions, the water gas shift equilibrium (Eq. 7) might be another important reaction which contributes to the observed product distribution.

$$
\mathrm{CO}+\mathrm{H}_{2} \mathrm{O} \leftrightarrow \mathrm{CO}_{2}+\mathrm{H}_{2}
$$

The surface chemistry of the methane oxidation on $\mathrm{Pt}$ has also been studied with respect to $\mathrm{C} 2$ formation and some mechanistic picture can be extracted, even though experimental conditions vary widely.

Somorjai et al. report methane dissociation on the least reactive Pt crystal face (111) at temperatures as low as $250 \mathrm{~K}$ [13] without evidence of the nature of the dissociation products. In a further study [14] over a temperature range from $300 \mathrm{~K}$ to $500 \mathrm{~K}$ and 1 Torr pressure, the authors report SFG and STM data showing the formation of $\mathrm{CH}_{3}$ groups, carbon and hydrogen at the $\mathrm{Pt}$ surface. C-C coupling between $\mathrm{CH}_{3}$ and $\mathrm{C}$ forming ethylidyne $\left(\mathrm{C}_{2} \mathrm{H}_{3}\right)$ is reported at $400 \mathrm{~K}$. Ethylidyne seems to be an intermediate because it dissociates at higher temperatures into $\mathrm{C}_{2} \mathrm{H}$ and $\mathrm{CH}$. The surface chemistry of $\mathrm{CH}_{3}$ on $\mathrm{Pt}$ (111) was also studied by depositing $\mathrm{CH}_{3}$ from gas phase pyrolysis of azomethane $[15,16]$. In [15], the authors do not observe any coupling of two $\mathrm{CH}_{3}$ species rather than a competition between hydrogenation to $\mathrm{CH}_{4}$ and further decomposition to surface carbon. In [16] higher methyl coverages were realized and TDS measurements showed high temperature ( 350 to $650 \mathrm{~K}) \mathrm{H}_{2}$ desorption typical for decomposition of $\mathrm{C}_{2} \mathrm{H}_{\mathrm{x}}$ species. From this observation the authors conclude on $\mathrm{C}$-C coupling at the $\mathrm{Pt}$ surface but probably by $\mathrm{CH}_{\mathrm{x}}$ species with $\mathrm{x}<3$. Results of dissociative methane adsorption by King et al. [17] on Pt (110) give indications of C-C coupling to $\mathrm{C}_{2} \mathrm{H}$ above $500 \mathrm{~K}$ and high coverages. However, also these $\mathrm{C} 2$ species were found to decompose at temperatures above $650 \mathrm{~K}$. It can be summarized that in absence of oxygen a narrow temperature range ( $400 \mathrm{~K}$ to $650 \mathrm{~K}$ ) exists for $\mathrm{C}-\mathrm{C}$ coupling on Pt, probably not by $\mathrm{CH}_{3}$ but $\mathrm{CH}_{\mathrm{x}}(\mathrm{x}<3)$ species. However, all $\mathrm{C} 2$ products formed are labile and decompose at higher temperature.

More relevant for the present work are surface science studies with oxygen present at the Pt surface [10, 18]. The result of these studies is that no $\mathrm{C} 2$ formation is observed if molecular or atomic oxygen is present on the $\mathrm{Pt}$ surface. Under oxidizing conditions $\mathrm{CO}$ and $\mathrm{CO}_{2}$ are the only carbon containing products. Also atmospheric pressure studies of the methane partial oxidation on Pt-coated monoliths [19] and on $\mathrm{Pt}$ and $\mathrm{Pt} / \mathrm{Rh}$ gauzes [20] indicate that $\mathrm{H}_{2}, \mathrm{CO}, \mathrm{H}_{2} \mathrm{O}$ and $\mathrm{CO}_{2}$ are formed via surface reactions. In summary, oxidative coupling of $\mathrm{C} 1$ to $\mathrm{C} 2$ species on a $\mathrm{Pt}$ surface under methane partial oxidation conditions is very unlikely.

As there is a formation of $\mathrm{C}_{2}$ products under high temperature conditions $\left(\mathrm{T}>1000^{\circ} \mathrm{C}\right)$ where not only surface but also gas reactions can occur $[20,21]$ the question arises what role platinum plays in this case. It is not clear how the platinum surface influences gas phase radical chain reactions and, with view on the oxidative coupling of methane on oxide catalysts, whether radicals desorb from the $\mathrm{Pt}$ surface.

As reviewed by Mackie [22], the relative concentration and the rate by which key radical species (e.g. H., R. $\mathrm{RO}, \mathrm{RO}_{2} \cdot \mathrm{HO}_{2}$, and $\mathrm{OH} \cdot(\mathrm{R}=$ organic rest $)$ ) react in the gas phase determines whether coupling products, oxygenates or total oxidation products are formed. Generally, gas phase radical reactions are unselective leading to the thermodynamic stable products under reaction conditions and their rate increase with pressure because of the increasing collision frequency among the gas molecules.

A numerical study by Deutschmann and Schmidt [19] showed, that at pressures of $1 \mathrm{MPa}$ and a catalyst temperature of $1188 \mathrm{~K}$, gas phase chemistry downstream the catalyst foam starts to influence the ratio between partial oxidation products $\left(\mathrm{H}_{2}, \mathrm{CO}\right)$ and total oxidation products $\left(\mathrm{CO}_{2}\right.$ and $\left.\mathrm{H}_{2} \mathrm{O}\right)$. It was found that downstream gas phase chemistry shifts the product distribution towards $\mathrm{CO}_{2}$ and $\mathrm{H}_{2} \mathrm{O}$, reducing the syngas selectivity by about $2 \%$.

Very pronounced seems the impact of gas phase chemistry on the formation of $\mathrm{C} 2$ coupling products $\mathrm{C}_{2} \mathrm{H}_{6}$, $\mathrm{C}_{2} \mathrm{H}_{4}, \mathrm{C}_{2} \mathrm{H}_{2}$. Numerical studies on a Pt-gauze catalyst report $\mathrm{C} 2$ product formation downstream the gauze [23, 24]. By coupling a microkinetic surface model with a microkinetic gas phase model this $\mathrm{C} 2$ formation was attributed to coupling of $\mathrm{CH}_{3}$. radicals in the gas phase $[23,24]$. Even 

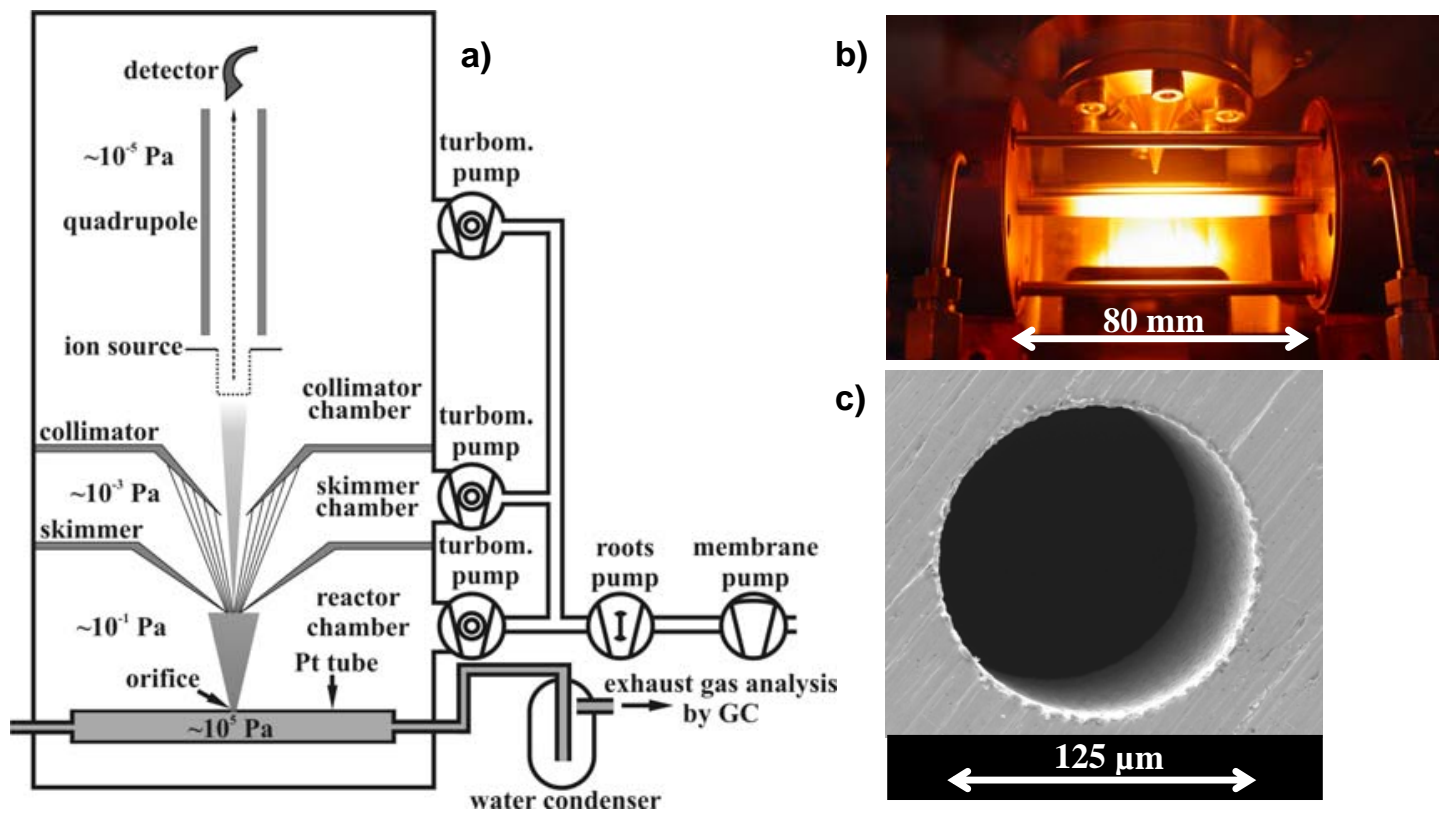

Fig. 1: a) Scheme of the MBMS set up, b) reactor under operation and c) image of the orifice

though there is no experimental proof, the simulations in $[23,24]$ indicate that methyl radicals do not desorb from the catalyst surface but are created in pure gas phase reactions downstream the gauze. This numerical result is in line with matrix isolation EPR studies by Lunsford et al. which verified the absence of $\mathrm{CH}_{3}$. desorption from Pt [25] up to temperatures of $900^{\circ} \mathrm{C}$. It seems that Pt behaves differently than strong basic oxide catalysts (e.g. $\mathrm{MgO}, \mathrm{La}_{2} \mathrm{O}_{3}$, ) from which $\mathrm{CH}_{3}$. radicals desorb into the gas phase as shown by matrix isolation EPR and photoionization mass spectrometry $[2,26]$. What has been experimentally verified on $\mathrm{Pt}$ is the presence of $\mathrm{OH}$ - radicals over the Pt surface during methane oxidation using laser induced fluorescence spectroscopy [27]. According to [27] where the LIF studies were also complemented by numerical simulations, the $\mathrm{OH}$. radicals originate from purely homogeneous reactions and the gas phase chemistry is rather suppressed by $\mathrm{Pt}$ than supported. In an earlier LIF study by Marks and Schmidt also $\mathrm{OH} \cdot$ desorption was observed [28].

It can be summarized that the high rate by which the methane oxidation proceeds over many catalysts, coupled with a high rate of heat generation leads to a complicated non-linear network of surface and gas reactions. Surface and gas chemistry are coupled by mass and heat transport which are often slower than the chemical reactions. Apart from scattered experimental results and numerical predictions, not much is known about the interplay between surface and gas chemistry during partial oxidation of methane on Pt. The present work presents a first in-situ investigation of the radical chemistry in the gas phase for the methane oxidation on $\mathrm{Pt}$ under partial oxidation conditions $(\mathrm{C} / \mathrm{O}=$ 0.6), atmospheric pressure and temperatures up to $1300{ }^{\circ} \mathrm{C}$.

\section{Experimental}

\section{2-1- Reactor and MBMS}

The use of a Molecular Beam Mass Spectrometer (MBMS) equipped with a high temperature catalytic wall reactor [21] allows studying the methane CPO in situ. The setup is shown schematically in Fig. 1a. The catalytic wall reactor consists of a platinum tube $(99.95 \%$ purity, Ögussa, length $=100 \mathrm{~mm}, \mathrm{ID}=4.4 \mathrm{~mm}, \mathrm{OD}=5.0 \mathrm{~mm}$ ) placed between two cooled copper clamps inside a vacuum chamber. The reactor was fed with a gas mixture of $490 \mathrm{ml} / \mathrm{min}$ methane, $410 \mathrm{ml} / \mathrm{min}$ oxygen and $100 \mathrm{ml} / \mathrm{min}$ inert gas as internal standard (Ar or He), resulting in a total flow of $1000 \mathrm{ml} / \mathrm{min}$ (STP conditions). Typically the feed stoichiometry is characterized by the $\mathrm{C} / \mathrm{O}$ ratio, which is the ratio of carbon to oxygen atoms in the feed. The used mixture corresponds to a $\mathrm{C} / \mathrm{O}$ ratio of 0.6. Gases were supplied from storage cylinders via mass flow controllers $\left(\mathrm{CH}_{4}\right.$ (99.95\%), $\mathrm{O}_{2}$ (99.999\%), He (99.999\%), $\mathrm{H}_{2}$ (99.999\%), $\operatorname{Ar}(99.999 \%)$ and synthetic air (99.999\%), all Westfalen).

The reaction is started by passing an electric current through the tube leading to resistive heating. Once the reaction started at around $600{ }^{\circ} \mathrm{C}$, it can run autothermally, or, with extra heating, at temperatures up to $1300{ }^{\circ} \mathrm{C}$ (Fig. 1b). All experiments were conducted at pressures close to atmospheric (104 to $113 \mathrm{kPa}$ ). The outer tube wall is kept under vacuum in the reactor chamber (approx. $10^{-1} \mathrm{~Pa}$ under operation). A small gas portion is sampled directly from above the reacting surface and expanded through an orifice (Ø $125 \mu \mathrm{m}$, Fig. 1c in the middle of the Pt reactor wall) into a three stage pumped vacuum background. The collision frequency between the molecules inside this free jet expansion drops to zero within microseconds preventing further reaction. An arrangement of differentially pumped skimmer 
and collimator cones forms a molecular beam axially aligned with the mass spectrometer.

The quadrupole mass spectrometer (QMS, HAL IV Epic Hiden) allows analysis of the gas components in the formed molecular beam. Radicals can be selectively detected in presence of interfering species $($ same $\mathrm{m} / \mathrm{z}$ ) by threshold ionization. Here, the energy of the ionizing electrons is adjusted high enough to ionize the radical but lower than the appearance energy (fragmentation) from other molecules $[29,30]$.

Axial temperature profiles of the tube reactor are measured by line scanning optical pyrometry (IMPAC IGAR 12-LO ratio pyrometer). Fast scanning, by using a mirror and a small angle step motor $\left(0.45^{\circ}\right.$ per step $)$, allows recording temperatures approximately every $4 \mathrm{~mm}$. The stepper motor is controlled by a Lab View program. All temperature values reported in this work are maxima of the corresponding profiles. After water removal in a reflux condenser, the reactor exhaust product composition is analyzed by on-line GC and GC-MS. The gas chromatograph (Varian CP-3800) is equipped with two columns (Molsieve and Hayesep S). During sample injection both columns are connected in series. All gases enter at first the Hayesep S column where the hydrocarbons and $\mathrm{CO}_{2}$ are retained and inert gases, oxygen and $\mathrm{CO}$ reach the Molsieve column. After this pre-separation, the columns are switched to a parallel mode and the effluent substances are analyzed. Inorganic compounds are detected by a thermal conductivity detector (TCD) and hydrocarbons are measured with a flame ionization detector (FID).

For the GC-MS analysis a second MS (OmnistarPfeiffer Vacuum) is connected directly in front of the TCD inlet. The scan time for a complete MS spectrum (1 to $80 \mathrm{amu}$ ) is with approx. $4 \mathrm{~s}$ much smaller than the FWHM of the analyzed GC peaks (10 s).

\subsection{GC-quantification}

The analysis of the exhaust gases of the reactor is performed without internal standard, because neither Ar nor $\mathrm{He}$ can be used with the GC. Ar and $\mathrm{O}_{2}$ overlap in the Molsieve column and He is used as carrier gas. $\mathrm{N}_{2}$ can not be used as internal standard because it interferes with $\mathrm{CO}$ in the MS.

Instead, the quantification is performed by using the known molecular inlet flows $\boldsymbol{F}_{\mathrm{CH}_{4}}^{\text {in }}$ and $\boldsymbol{F}_{\mathrm{O}_{2}}^{\text {in }}$.

Under the conditions used the deposition of carbon in the reactor and the formation of condensable oxygenates is virtually zero (steady state). Therefore a carbon atom balance with $\mathrm{F}$ denoting a molar flow rate gives:

$F_{C}^{\text {in }}=F_{C}^{\text {out }}=F_{C H_{4}}^{\text {in }}$

As every carbon containing species $(\mathrm{x})$ can be detected by the $\mathrm{GC}$ the total $\mathrm{C}$ amount is given by:

$$
C_{C}^{g e s}=\sum v_{X} C_{X}
$$

$(\mathrm{C}=$ concentration in $\mathrm{Vol} \%, v=$ number of $\mathrm{C}$ atoms in $\mathrm{X})$ Individual flow rates for every carbon containing species can be calculated using:

$$
F_{X}=\frac{F_{C}^{i n}}{C_{C}^{g e s}} \cdot C_{X}
$$

Assuming ideal gases, the flow rate of the non $\mathrm{C}$ containing molecules $\left(\mathrm{O}_{2}\right.$ and $\left.\mathrm{H}_{2}\right)$ can be calculated from:

$$
F_{\mathrm{O}_{2}}=\frac{F_{C}^{\text {in }}}{C_{C}^{\text {ges }}} \cdot C_{\mathrm{O}_{2}}
$$

The molar flow rate of water is calculated from an oxygen atom balance:

$$
F_{\mathrm{H}_{2} \mathrm{O}}^{\text {out }}=2 \cdot F_{\mathrm{O}_{2}}^{\text {in }}-F_{C O}^{\text {out }}-2 \cdot F_{\mathrm{CO}_{2}}^{\text {out }}-2 \cdot F_{\mathrm{O}_{2}}^{\text {out }}
$$

With all flow rates known the selectivities $(\mathrm{S})$ and conversions $(\mathrm{X})$ can be determined:

$$
S_{X}=\frac{F_{X} \cdot v_{X}}{\left(F_{C H_{4}}^{\text {in }}-F_{C H_{4}}^{\text {out }}\right)}
$$

and

$$
X_{\mathrm{CH}_{4}}=\frac{F_{\mathrm{CH}_{4}}^{\text {out }}}{\left(F_{\mathrm{CH}_{4}}^{\text {in }}-F_{\mathrm{CH}_{4}}^{\text {out }}\right)}
$$

\subsection{Radical Measurements}

\subsubsection{Electron Energy Spread and Offset}

To determine the onset of the gradually increasing ion signal in threshold ionization measurements, the energy spread and the energy offset of the ionizing electrons have to be determined. In an earlier publication [21], the authors showed that the energy spread of the ion source used in the molecular beam mass spectrometer is Gaussian and any measured ionization efficiency curve, is a convolution between this Gaussian energy spread function and the true but in most cases unknown ionization efficiency curve $\mathrm{P}_{\mathrm{i}}(\mathrm{E})$. As the single ionization of atoms close to the threshold can be approximated by Wannier's threshold law Eq. (15) [31], the ionization efficiency curve for the single ionization of $\mathrm{Ar}$ at $40 \mathrm{amu}$ was measured from 15.0 to $17.5 \mathrm{eV}$ and energy spread and offset were obtained by a nonlinear fit of the discretized convolution integral Eq. (16) to the threshold data (Fig. 2). In Eq. (16), i(V) is the measured ionization efficiency curve (ion signal vs. set electron energy V), $\mathrm{C}$ a proportionality constant, $\sigma$ the standard deviation of the Gaussian energy spread, $\mathrm{j}$ the summation index and IP the 


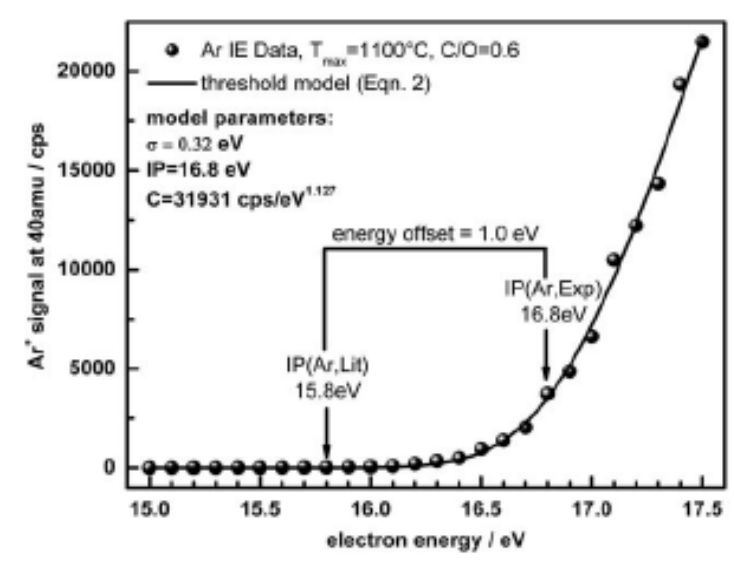

Fig. 2: Experimental threshold data for Ar single ionization (globes) and nonlinear fit of Eq.() (solid line) to determine the electron energy spread and offset [32]

offset shifted ionization potential of Ar. The summation starts at the ionization potential because there is no ionization, i.e. $\mathrm{P}_{\mathrm{i}}(\mathrm{E})=0$, for electron energies lower than the ionization potential. As the ion source allows energy steps of $0.1 \mathrm{eV}, \Delta \mathrm{E}$ was chosen to be 0.1 . For a more detailed description of this procedure the reader is referred to [21].

$$
\begin{aligned}
& P_{i}(E)=C \cdot(E-I P)^{1.127} \quad E \geq I P \\
& i(V)=\frac{C}{\sigma \sqrt{2 \pi}} \sum_{j=0}^{\infty} \operatorname{Exp}\left(-\frac{(I P+j \cdot \Delta E-V)^{2}}{2 \sigma^{2}}\right) \cdot(j \cdot \Delta E)^{1.127} \cdot \Delta E
\end{aligned}
$$

The threshold ionization measurements of the internal standard Ar have been repeated for different reaction conditions. The slopes of the IE curves were found to depend on composition and temperature conditions in the reactor whereas electron energy offset and spread remain essentially constant. This can be understood because the slope of the IE curve depends on the Ar flow through the sampling orifice, which changes with changing experimental conditions, whereas energy spread and offset depend only on the ionizer in the mass spectrometer and not on the reactor conditions. On average, the electron energy offset was found to be $1.1 \mathrm{eV}$ and the energy spread $\sigma=0.31 \mathrm{eV}$. This means that radicals can be selectively detected with the MBMS if the appearance potential of any interfering ion is at least $2 \sigma=0.62 \mathrm{eV}$ higher than the ionization potential of the radical. The ionization potential of the target radical $\mathrm{CH}_{3}$. is $\mathrm{IP}\left(\mathrm{CH}_{3} \cdot\right)=9.84 \mathrm{eV}$ [33]. By means of thermodynamics it can be shown that the appearance potential of $\mathrm{CH}_{3}{ }^{+}$from any interfering ion $\mathrm{AP}\left(\mathrm{CH}_{3}{ }^{+} / \mathrm{CH}_{3}-\mathrm{R}\right)$, where $\mathrm{R}$ is an organic rest, must always be higher than $\operatorname{IP}\left(\mathrm{CH}_{3} \cdot\right)$ namely by the bond dissociation enthalpy of the $\mathrm{R}-\mathrm{CH}_{3}$ bond which is typically of the order of 3 to $4 \mathrm{eV} \mathrm{[30].} \mathrm{For}$ example, $\quad \mathrm{AP}\left(\mathrm{CH}_{3}{ }^{+} / \mathrm{CH}_{4}\right)=14.01 \mathrm{eV}$ [34] and $\mathrm{AP}\left(\mathrm{CH}_{3}{ }^{+} / \mathrm{C}_{2} \mathrm{H}_{6}\right)=13.65 \mathrm{eV}$ [35]. Therefore it should be possible to detect $\mathrm{CH}_{3}$. radicals in presence of any interfering hydrocarbon molecule.

\subsubsection{Radical Quantification}

The method of radical quantification used in this work is based on the work of Singh, Coburn and Graves [36]. In this method, radicals are quantified by reference to an ion which is the product of a direct ionization process rather than a fragment and lies very close in mass to the radical ion (e.g. $\mathrm{CH}_{4}^{+}$for the radical ion $\mathrm{CH}_{3}{ }^{+}$). This ensures similar extraction efficiencies in the ionizer, similar quadrupole transmissions and similar detector sensitivities for both ions. If the signal of the stable ion (e.g. $\mathrm{CH}_{4}^{+}$) can be related to a concentration measure of its parent molecule in the reactor tube $\left(\mathrm{CH}_{4}\right)$, it is possible to calculate the concentration of the radical in the reactor. Eq. (17) shows the applied relationship for the quantification of $\mathrm{CH}_{3}$. radicals in this work. The radical concentration is obtained in units of a molar flow rate $\mathrm{F}$, as it is based on the methane molar flow rate at the orifice position, which itself is calculated from the known molar flow rate of the inert standard Ar. The other symbols in Eq. (17) are A, the slope of the ion signal close to the threshold; $\lambda$, the slope of the ionization cross section at the threshold (e.g. from NIST database [37, 38]); S, the mass spectrometer signal at an energy where Ar and $\mathrm{CH}_{4}$ ionize (in this work $25 \mathrm{eV}$ ) and $\mathrm{R}$, the response factor for the mass spectrometric detection of the stable ion $\left(\mathrm{CH}_{4}{ }^{+}\right)$based on the internal standard Ar. The slope was used in this case instead of individual ionization cross sections to minimize the error.

$$
F_{\mathrm{CH}_{3} \cdot}=\frac{A^{\mathrm{CH}_{3} \cdot \rightarrow \mathrm{CH}_{3}^{+}} \cdot \lambda^{\mathrm{CH}_{4} \rightarrow \mathrm{CH}_{4}^{+}}}{A^{\mathrm{CH}_{4} \rightarrow \mathrm{CH}_{4}^{+}} \cdot \lambda^{\mathrm{CH}_{3} \cdot \rightarrow \mathrm{CH}_{3}^{+}}} \cdot F_{\mathrm{Ar}}^{i n} \cdot \frac{S_{\mathrm{CH}_{4}}^{25 \mathrm{eV}}}{S_{\mathrm{Ar}}^{25 \mathrm{~V}} \cdot \mathrm{R}_{\mathrm{CH}_{4} / \mathrm{Ar}}^{\mathrm{cal}}}
$$

Because the molecular beam formation from a free jet expansion is a very complex process the error bar for this quantification method can not yet been specified. Dedicated experiments indicate a strong and complicated dependence of the mass spectrometer signal on species concentration, temperature and pressure in the reactor and on the orifice-skimmer distance. Further experiments are necessary to investigate how these variables influence species of different mass (e.g. $\mathrm{CH}_{4}$ and $\mathrm{Ar}$ ) which determines the error of the quantification procedure. Currently, $\mathrm{CH}_{4}$ and $\mathrm{Ar}$ are considered to behave the same in the molecular beam forming process. However, the order of magnitude of the calculated $\mathrm{CH}_{3}$. radical flow rates agrees with preliminary numerical simulations performed on the reactor using the CRESLAF code in CHEMKIN (not yet published). 


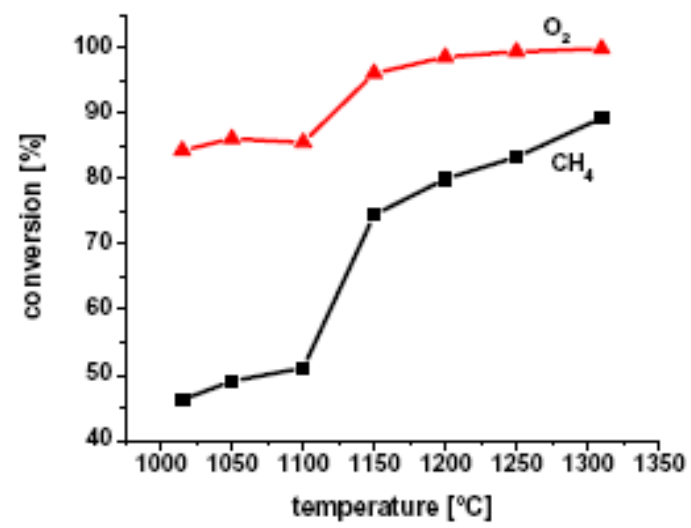

Fig. 3: Conversion of reactants during $\mathrm{CPO}$ of methane depending on $\mathrm{T}$

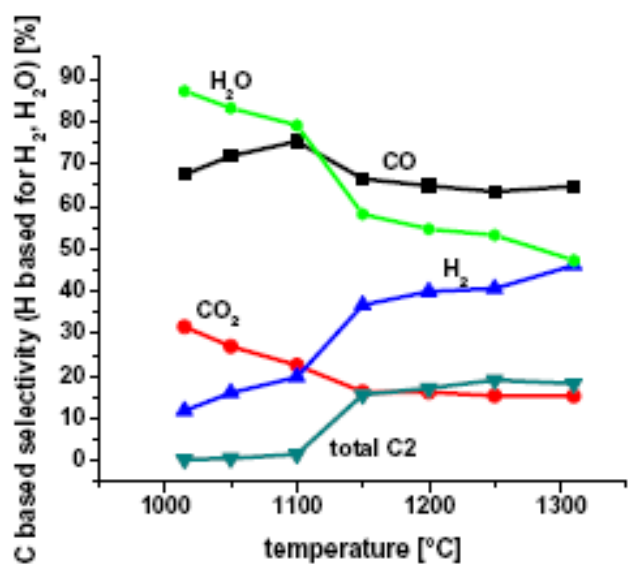

Fig. 4: Selectivities of products during methane $\mathrm{CPO}$

\section{Results}

\subsection{Catalytic Data}

At temperatures lower than about $1100{ }^{\circ} \mathrm{C}$, unconverted methane and oxygen were found by on line GC analysis of the reactor effluent stream (Fig. 3). A significant increase of the reactant conversion is noticed by increasing the temperature above $1100{ }^{\circ} \mathrm{C}$. Upon increasing the temperature by only $50{ }^{\circ} \mathrm{C}$ from 1100 to $1150{ }^{\circ} \mathrm{C}$, the $\mathrm{O}_{2}$ conversion increases in a step like manner from 85 to 95 $\%$ whereas methane conversion increases from 50 to $75 \%$. Upon further heating, the $\mathrm{O}_{2}$ conversion rises slowly to $100 \%$ whereas the $\mathrm{CH}_{4}$ conversion increases linearly to about $90 \%$.

Below $1100{ }^{\circ} \mathrm{C}$, the reaction products are mainly $\mathrm{H}_{2}$, $\mathrm{CO}, \mathrm{H}_{2} \mathrm{O}$ and $\mathrm{CO}_{2}$ formed by oxidation reactions, reforming reactions and water gas shift as discussed in the introduction. $\mathrm{CO}$ and $\mathrm{H}_{2} \mathrm{O}$ dominate and only traces of ethane are formed as $\mathrm{C} 2$ coupling products (Fig. 4). The step like change in conversion observed upon heating from 1100 to $1150{ }^{\circ} \mathrm{C}$ is also reflected in the selectivity patterns. Both, the selectivity to $\mathrm{H}_{2}$ and $\mathrm{C} 2$ show a step like increase from 20 to $35 \%$ and $\sim 0$ to $15 \%$ respectively. C2 formation in- creases at the expense of $\mathrm{CO}$ and $\mathrm{CO}_{2}$ formation, for which the selectivity drops.

As the temperature is increased from 1150 to $1300^{\circ} \mathrm{C}$, the selectivity to $\mathrm{H}_{2}$ and $\mathrm{C} 2$ rises further and those of $\mathrm{H}_{2} \mathrm{O}, \mathrm{CO}$ and $\mathrm{CO}_{2}$ drop but not as steeply as between $1100-1150{ }^{\circ} \mathrm{C}$.

After the sharp temperature rise from 1100 to 1150 ${ }^{\circ} \mathrm{C}$, not only ethane, ethylene and acetylene are suddenly detected by GC, also small but noticeable amounts of higher unsaturated hydrocarbons. Several of these species could be identified by GC-MS and comparison with literature data from NIST [37] and reference chromatograms [39]. Four examples are presented in Fig. 5. The peaks marked with stars arise from water eluting from the column and the MS background $\left(\mathrm{N}_{2}, \mathrm{O}_{2}, \mathrm{CO}_{2}, \mathrm{Ar}\right)$. The background signal of the other masses is stable between 0.5 and $1 \cdot 10^{-11}$ Amperes and therefore five times lower than the smallest studied peak. A list with all identified coupling products with their maximal achieved selectivities is given in Tab. 1. At temperatures around $1310^{\circ} \mathrm{C}$, noticeable amounts of benzene are formed, a typical coke precursor. Indeed, higher $\mathrm{C} / \mathrm{O}$ ratios than 0.6 could not be investigated at such high temperatures as coke formation caused a plugging of the sampling orifice.

Tab. 1: Maximal concentrations of detected higher hydrocarbons depending on the temperature during methane $\mathrm{CPO}$

\begin{tabular}{ccc}
\hline Hydrocarbon & max. selectivity $/ \%$ & $\begin{array}{c}\text { at } \mathrm{T} / \\
{ }^{\circ} \mathrm{C}\end{array}$ \\
\hline Acetylene & 17.2 & 1310 \\
Ethylene & 4.4 & 1150 \\
Ethane & 1.5 & 1150 \\
Allene & 0.2 & 1200 \\
Propyne & 0.5 & 1200 \\
1-Butene-3-yne & 0.3 & 1200 \\
1,3-Butadiyne & 0.8 & 1310 \\
Benzene & 0.7 & 1310 \\
\hline
\end{tabular}

\subsection{Radical Measurements during Methane $C P O$}

With the appearance of $\mathrm{C} 2$ and other coupling products at temperatures $\geq 1150{ }^{\circ} \mathrm{C}$ also methyl radicals are detected. In Fig. 6, mass spectra and IE curves are compared for 1015 and $1310{ }^{\circ} \mathrm{C}$. At $1015{ }^{\circ} \mathrm{C}$, the onset of the IE curve is at $14 \mathrm{eV}$, which corresponds to the appearance potential of $\mathrm{CH}_{3}{ }^{+}$from $\mathrm{CH}_{4}(14.01 \mathrm{eV})$ [34]. The inset in the left side of Fig. 6 shows the mass spectrum at an ionizing energy of $11.9 \mathrm{eV}$. The peak at $15 \mathrm{amu}$ is close to zero, as there are no $\mathrm{CH}_{3}$. radicals and methane does not dissociate at this low energy. At $1310{ }^{\circ} \mathrm{C}$, the IE curve increases from $9.8 \mathrm{eV}$ on, a clear indication of $\mathrm{CH}_{3} \cdot$ radicals 

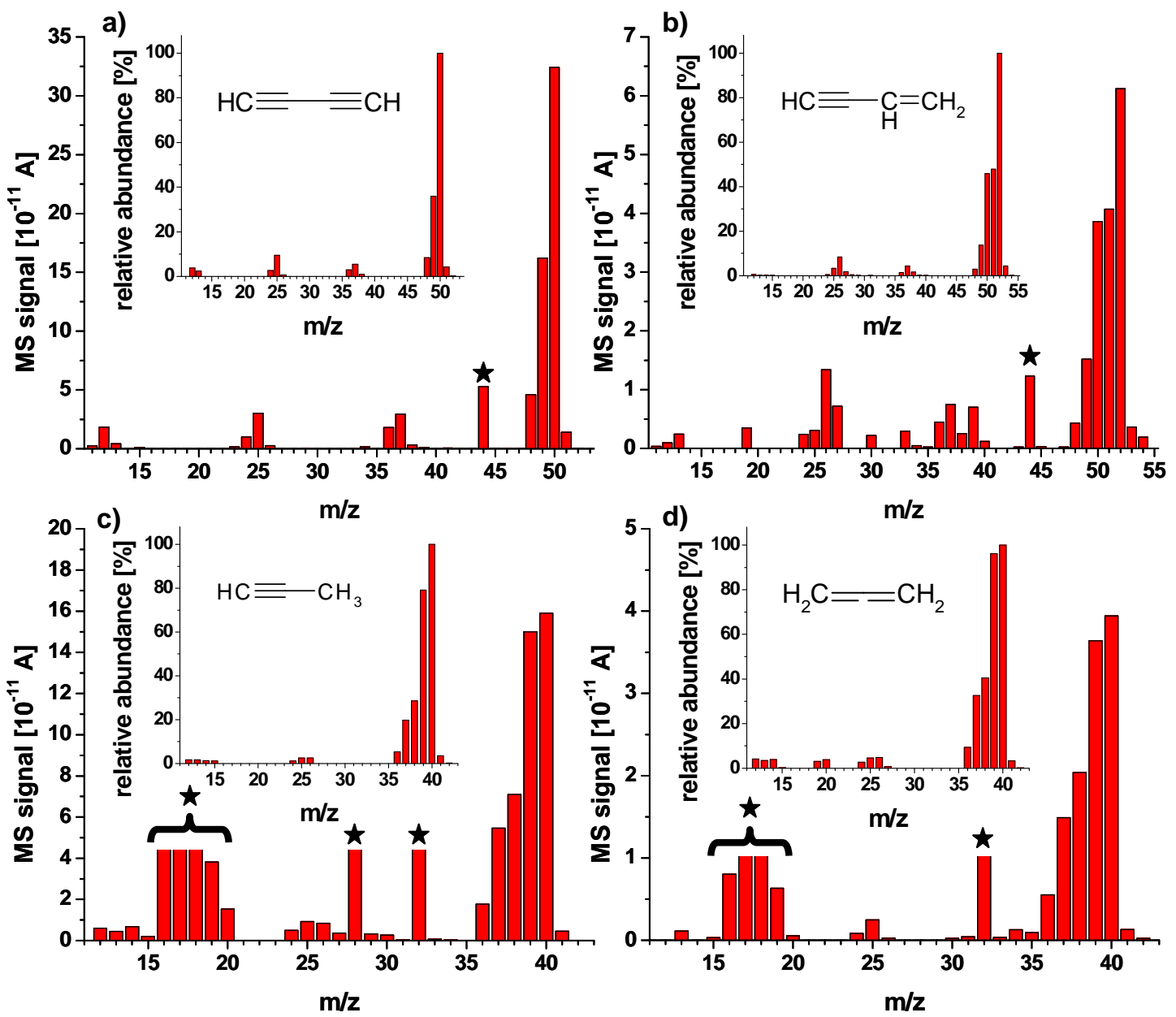

Fig. 5: Four unsaturated hydrocarbons identified by GC-MS. a) 1,3-butadiyne; b) 1-buten-3-yne; c) propyne; d) allene. The insets present the NIST data [37] for comparison.

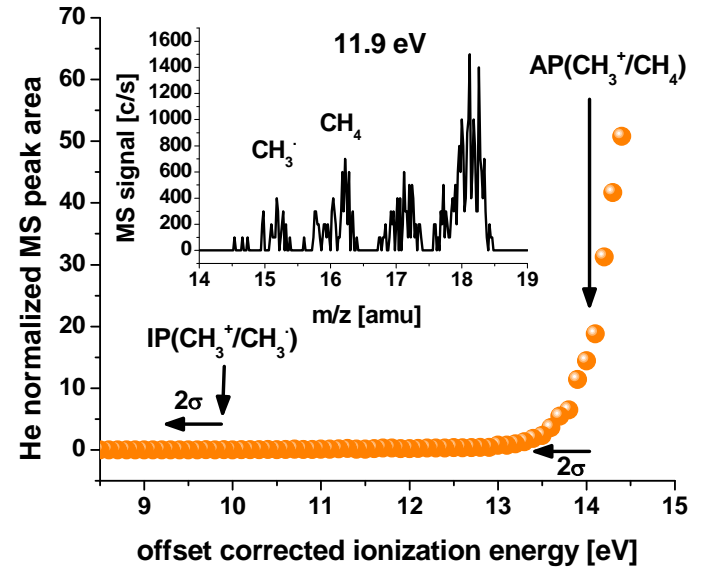

a)

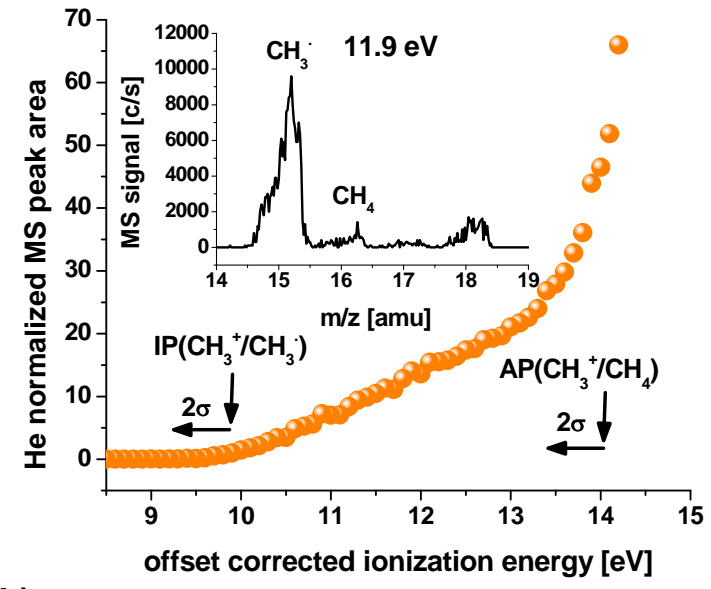

b)

Fig. 6: IE curves at $15 \mathrm{amu}$ for the detection of $\mathrm{CH} 3$ - radicals by threshold ionization at a) $1015{ }^{\circ} \mathrm{C}$ and b) $1310{ }^{\circ} \mathrm{C}$

$\left(\mathrm{IP}\left(\mathrm{CH}_{3}{ }^{+} / \mathrm{CH}_{3} \cdot\right)=9.84 \mathrm{eV}\right)$ [33]. At higher electron energies the curve increases even more steeply caused by $\mathrm{CH}_{3}{ }^{+}$ fragment formation from methane at $14 \mathrm{eV}$. Without $\mathrm{CH}_{3}$. radicals $\left(1015{ }^{\circ} \mathrm{C}\right)$, the IE curve remains close to zero until the fragmentation processes begin. The inset at the right side of Fig. 6 shows again the mass spectrum at $11.9 \mathrm{eV}$ ionizing energy. Now $\mathrm{CH}_{3}$. radicals produce a strong signal at $15 \mathrm{amu}$ whereas $\mathrm{CH}_{4}$ is barely ionized at $16 \mathrm{amu}$ without dissociation to $\mathrm{CH}_{3}^{+}$. 


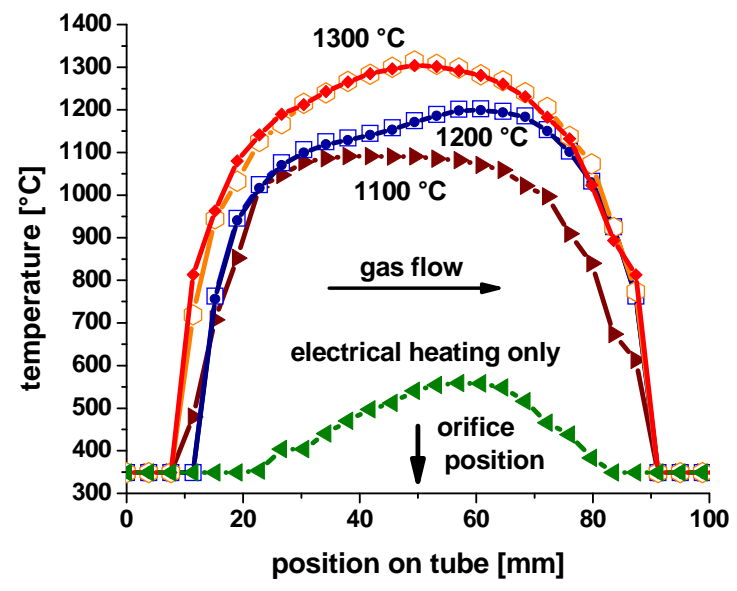

Fig. 7: Axial temperature profiles of the Pt wall reactor with electrical heating only and during operation at 1100 ${ }^{\circ} \mathrm{C}, 1200{ }^{\circ} \mathrm{C}$ and $1300{ }^{\circ} \mathrm{C}$

\subsection{Temperature Profiles}

Line scanning pyrometry allows contact-free measurement of temperature profiles across the Pt tube during methane CPO. Changes in the temperature profiles upon ignition or increase of the heating current can be correlated with the product gas composition from the QMS and GCMS measurements to give a more detailed view of mechanistic changes.

Under all conditions, the tube ends are cold and the hot zone is confined to the middle of the tube with a length of about 70 to $80 \mathrm{~mm}$ (Fig. 1b). At $\mathrm{C} / \mathrm{O}=0.6$, the methane $\mathrm{CPO}$ ignites typically around $600{ }^{\circ} \mathrm{C}$. If the reaction runs autothermally at $\mathrm{C} / \mathrm{O}=0.6$, a maximum temperature of about $1000{ }^{\circ} \mathrm{C}$ is reached. The tube temperature is further increased by electric heating, reaching $1100{ }^{\circ} \mathrm{C}(23 \mathrm{~W})$, $1200{ }^{\circ} \mathrm{C}(139 \mathrm{~W})$ and $1300{ }^{\circ} \mathrm{C}(225 \mathrm{~W})$ as shown in Fig. 7. The temperature profile of the tube for a particular $\mathrm{C} / \mathrm{O}$ ratio is very reproducible, i.e. the same profile is measured after switching back from experiments at other $\mathrm{C} / \mathrm{O}$ ratios. This is illustrated in Fig. 7, where two profiles at $1200{ }^{\circ} \mathrm{C}$ and two profiles at $1300{ }^{\circ} \mathrm{C}$ are superimposed which have been measured at intervals of $30 \mathrm{~min}$. This reproducibility indicates that the reactor reaches steady state quickly.

The temperature profile of the heated tube without gas flow (not shown) is symmetric with a maximum in the tube center as can be expected for electric heating of an ohmic resistor. With gas flow, but without reaction, the heat is convectively transported within the stream towards the outlet, shifting the temperature maximum in the same direction ("electrical heating only"). When sufficient heating power is provided, oxidation reactions start at the platinum surface. The heat liberated causes a self-acceleration of these exothermic surface reactions, more heat is liberated and reactor light-off is observed. The reaction zone proceeds towards the reactor inlet where fresh reactants enter. Between autothermal reactor operation and the ignition of gas phase chemistry electrical heating and surface reactions result in a temperature profile with a $40 \mathrm{~mm}$ wide, slightly declining plateau extending from $30 \mathrm{~mm}$ to $70 \mathrm{~mm}$ axial coordinates. The gradual temperature decrease in this section might be due to chemical cooling by endothermic steam reforming. Only $\mathrm{CO}, \mathrm{CO}_{2}, \mathrm{H}_{2}$ and $\mathrm{H}_{2} \mathrm{O}$ are the products in this surface chemistry regime in agreement with the literature.

Between $1100{ }^{\circ} \mathrm{C}$ and $1200{ }^{\circ} \mathrm{C}$ a second ignition behavior is observed leading to a temperature maximum located towards the tube outlet. Further electrical heating up to $1300{ }^{\circ} \mathrm{C}$ leads to a symmetrical temperature profile with the maximum in the tube center.

\section{Discussion}

The following picture of the methane CPO in the reactor can be derived combining catalytic results, mass spectrometric radical measurements and temperature profiles. Around $600{ }^{\circ} \mathrm{C}$ the reactor lights-off by ignition of surface reactions. This value is in good agreement with literature values for surface ignition of $\mathrm{CH}_{4} / \mathrm{O}_{2}$ mixtures on $\mathrm{Pt}$ at $\mathrm{C} / \mathrm{O}$ $=0.6$ [40]. The autothermal operation temperature at $\mathrm{C} / \mathrm{O}=$ 0.6 is around $1000{ }^{\circ} \mathrm{C}$. Between autothermal operation and heating to $1100{ }^{\circ} \mathrm{C}$, exothermic surface reactions dominate the reaction network. In agreement with the literature [19] $\mathrm{H}_{2}, \mathrm{CO}, \mathrm{H}_{2} \mathrm{O}$ and $\mathrm{CO}_{2}$ are found as the main products which are probably formed by total oxidation, partial oxidation, steam reforming and water gas shift [12]. No radicals are detected indicating gas phase chemistry. $\mathrm{O}_{2}$ conversion is incomplete under these conditions which is not surprising because the ratio of residence time in the reactor to diffusion time from the tube center to the wall is close to unity. Together with the laminar flow profile (Reynolds number is estimated from 100 to 400 depending on the reaction conditions) some methane and oxygen remain unconverted in the bulk gas phase as they do not come in contact with the Pt surface.

If the heating power is further increased to raise the temperature above $1100{ }^{\circ} \mathrm{C}$, a second ignition behavior is observed and the temperature profile of the reactor develops a pronounced maximum located towards the outlet indicating a strong additional heat release (e.g. $1200{ }^{\circ} \mathrm{C}$ curve in Fig. 7). This second ignition point is further characterized by a step like increase in $\mathrm{O}_{2}$ and $\mathrm{CH}_{4}$ conversion $\left(\mathrm{O}_{2}\right.$ conversion approaches completion), the formation of $\mathrm{C} 2$ coupling products and the detection of $\mathrm{CH}_{3}$. radicals. In light of numerical simulations published in the literature [5], this second ignition can be attributed to the ignition of gas phase reactions. The ignition temperature of the gas phase reactions $\left(\sim 1150^{\circ} \mathrm{C}\right)$ is much higher than the ignition temperature of the catalytic reactions $\left(\sim 600^{\circ} \mathrm{C}\right)$ because gas phase reactions have much higher activation barriers. Another cause of the delayed gas phase ignition might be that the gas temperature is lower than the surface temperature due to the finite rate of heat transport from the surface to the gas phase causing a slower rise of the gas phase temperature compared to the surface temperature. Also chemi 


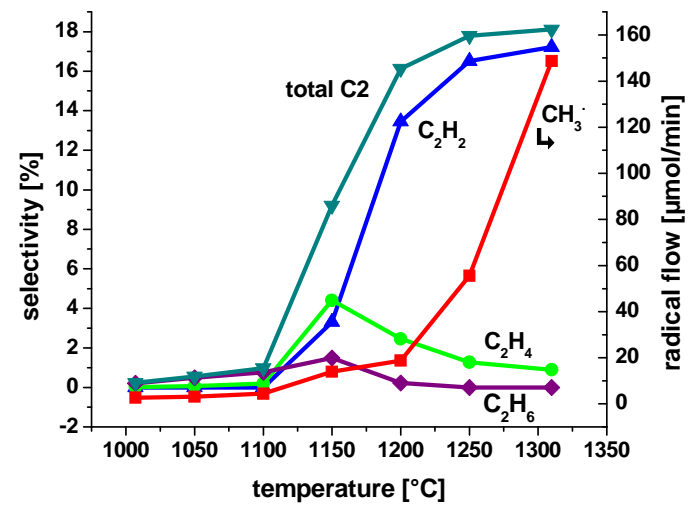

Fig. 8: Selectivities of ethane, ethylene and acetylene and comparison of $\mathrm{CH}_{3}$. flows depending on the temperature

cal reasons (e.g. radical exchange) might influence the start of gas phase reactions.

Fig. 8 displays the selectivity for the formation of the $\mathrm{C} 2$ coupling products (total $\mathrm{C} 2$, ethane, ethylene, acetylene) as well as the molar flow rate of $\mathrm{CH}_{3}$. radicals in dependence of the temperature.

There is a correlation between the formation of $\mathrm{CH}_{3}$. radicals and the formation of $\mathrm{C} 2$ coupling products. The more $\mathrm{CH}_{3}$. radicals are produced, the more $\mathrm{C} 2$ coupling products are formed. This finding indicates that $\mathrm{C} 2$ coupling products originate from a recombination of $\mathrm{CH}_{3}$. radicals in the gas phase (Eq. 18). This is the first experimental verification of the numerical predictions by Quiceno et al. [20, 23]

$\mathrm{CH}_{3} \cdot+\mathrm{CH}_{3} \cdot \rightarrow \mathrm{C}_{2} \mathrm{H}_{6}$

The different shapes of the $\mathrm{CH}_{3}$. radical curve and the total $\mathrm{C} 2$ formation curve result from the different sampling positions. While $\mathrm{CH}_{3}$. radicals are measured in the middle of the tube, $\mathrm{C} 2$ products are measured at the tube exit (see Fig. 1).

The fact that small amounts of ethane but no $\mathrm{CH}_{3}$. radicals are observed between the autothermal temperature of $1000{ }^{\circ} \mathrm{C}$ and the gas phase ignition point at around $1150{ }^{\circ} \mathrm{C}$ can be explained by a $\mathrm{CH}_{3} \cdot$ concentration below the detection limit of the method (low ppm range [21]). In light of the discussion of surface chemistry in the introduction it is not likely that $\mathrm{C} 2$ coupling products are formed on the Pt surface. The small ethane formation before gas phase ignition is rather due to coupling of $\mathrm{CH}_{3}$. radicals which are part of the radical pool formed by homogeneous reactions before ignition. Between 1000 and $1100{ }^{\circ} \mathrm{C}$ the main $\mathrm{C} 2$ product is ethane, at $1150{ }^{\circ} \mathrm{C}$ ethylene and at all higher temperatures acetylene in agreement with the thermodynamic trend [41]. $\mathrm{As}_{\mathrm{CH}_{2}}$. or $\mathrm{CH}$. radicals are not observed in the gas phase the formation of ethylene and acetylene does not occur by coupling of the aforementioned species but rather by dehydrogenation or oxidative dehydrogena- tion of ethane. This is also the common interpretation in the literature $[42,43]$.

$\mathrm{C}_{2} \mathrm{H}_{6} \rightarrow \mathrm{C}_{2} \mathrm{H}_{4}+\mathrm{H}_{2} \rightarrow \mathrm{C}_{2} \mathrm{H}_{2}+2 \mathrm{H}_{2}$

or

$\mathrm{C}_{2} \mathrm{H}_{6}+\mathrm{O}_{2} \rightarrow \mathrm{C}_{2} \mathrm{H}_{4}+\mathrm{H}_{2} \mathrm{O}+1 / 2 \mathrm{O}_{2} \rightarrow \mathrm{C}_{2} \mathrm{H}_{2}+2 \mathrm{H}_{2} \mathrm{O}$

If direct coupling of $\mathrm{CH}_{2}$. or $\mathrm{CH} \cdot$ was the formation mechanism to $\mathrm{C}_{2} \mathrm{H}_{4}$ and $\mathrm{C}_{2} \mathrm{H}_{2}$ respectively the species should be detected facing the high concentrations by which ethylene and in particular acetylene, are formed.

Similar to EPR results of Lunsford and coworkers [25], also the data in this work are in favor of an exclusive homogeneous generation of $\mathrm{CH}_{3}$ radicals during methane oxidation without $\mathrm{CH}_{3}$ desorption from the $\mathrm{Pt}$ surface. It is not plausible that an increase in temperature by $50{ }^{\circ} \mathrm{C}$ from 1100 to $1150{ }^{\circ} \mathrm{C}$ leads suddenly to a production and desorption of $\mathrm{CH}_{3}$. radicals from the surface. It is more likely that methyl radicals arise predominantly from gas phase reactions, initiated and sustained by heat release from the Pt surface. This interpretation would also be in agreement with the numerical predictions of Quiceno et al. [23, 24] showing that $\mathrm{CH}_{3}$ radicals are rather consumed than produced by a Pt surface. Pt is an extremely active oxidation catalyst and it is unlikely that an alkyl radical can desorb from the surface without being converted to $\mathrm{CO}$ or $\mathrm{CO}_{2}$. The lack of $\mathrm{CH}_{3}$ desorption is a clear difference between $\mathrm{Pt}$ and typical oxidative coupling catalysts like $\mathrm{Li} / \mathrm{MgO}$ or $\mathrm{La}_{2} \mathrm{O}_{3}$ where $\mathrm{CH}_{3}$. radical desorption plays a vital role in the mechanism $[44,45]$.

Whether $\mathrm{OH}$. radicals exist in the gas phase, as reported in the literature based on LIF results [27, 28], can not be inferred from the measurements. With large amounts of $\mathrm{CH}_{4}$ in the molecular beam it is impossible to measure $\mathrm{OH} \cdot$ by threshold ionization because ionization of methane molecules containing ${ }^{13} \mathrm{C}$ dominates the signal at $17 \mathrm{amu}$ $\left({ }^{13} \mathrm{C}^{1} \mathrm{H}_{4}\right)$. Methane ionizes at lower energies $\left(\mathrm{IP}\left(\mathrm{CH}_{4}\right)=\right.$ $12.6 \mathrm{eV}$ [34]) than $\mathrm{OH}$ radicals (13.2 eV [46]).

Other radicals that are typical for gas phase alkane oxidation reactions like $\mathrm{O} \cdot, \mathrm{HO}_{2} \cdot \mathrm{H} \cdot \mathrm{RO} \cdot$ and $\mathrm{RO}_{2}$. can be measured with the MBMS but were not detected under any of the investigated conditions. Also $\mathrm{Pt}_{\mathrm{x}} \mathrm{O}_{\mathrm{y}}$ species, which could be potential initiators of gas phase chemistry, were not detected in the gas phase using full mass scans up to $510 \mathrm{amu}$. Combining these results with information from the literature [47] it can be suggested that methyl radicals are created homogeneously in the gas phase by one of the following reactions:

$\mathrm{CH}_{4}+\mathrm{O}_{2} \rightarrow \mathrm{CH}_{3}+\mathrm{HO}_{2}$
$\mathrm{CH}_{4}+\mathrm{M} \rightarrow \mathrm{CH}_{3}+\mathrm{H}+\mathrm{M}$
$\mathrm{CH}_{4}+\mathrm{OH} \rightarrow \mathrm{CH}_{3}+\mathrm{H}_{2} \mathrm{O}$

In Eq. (22), $M$ denotes an inert collision partner like for example Ar. 


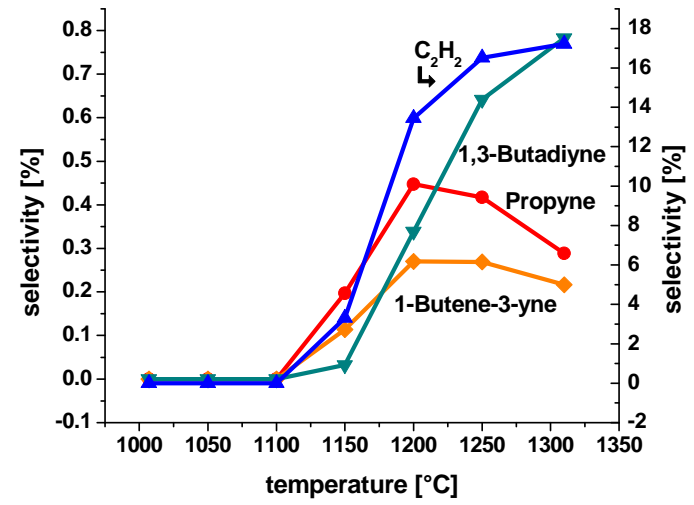

Fig. 9: Selectivities of C3 and C4 hydrocarbons in dependence of the acetylene formation

That fact that no other radicals than $\mathrm{CH}_{3}$. are observed does not mean that no other radicals are involved in the gas phase oxidation of methane it rather means that the other radicals react away so quickly that their steady state concentration is below the detection limit of the method (low ppm range [21]).

Obviously, $\mathrm{CH}_{3} \cdot$ radicals are comparably stable [48] and formed in large quantities compared to all other radical species in the reaction network. Indeed, the numerical simulations of the methane CPO on a Pt gauze by Quiceno et al. [24] show that $\mathrm{CH}_{3}$. radicals downstream the gauze have a higher concentration than $\mathrm{HO}_{2}$ and $\mathrm{OH}$.

The hypothesis, that the second reaction light off between $1100^{\circ} \mathrm{C}$ and $1150{ }^{\circ} \mathrm{C}$ is due to gas phase radical chemistry, is further supported by the observation of $\mathrm{C} 3$ and $\mathrm{C} 4$ coupling products. Various unsaturated higher hydrocarbons $\left(\mathrm{C}_{3} \mathrm{H}_{4}, \mathrm{C}_{4} \mathrm{H}_{4}\right.$ and $\left.\mathrm{C}_{4} \mathrm{H}_{2}\right)$ were identified in the reactor outlet by GC-MS; however, their concentrations never exceeded a few ppm. It can be expected that the formation mechanism of these products is similar to that for the $\mathrm{C} 2$ coupling products meaning that $\mathrm{C} 3$ products are formed by recombination of methyl and $\mathrm{C} 2$ alkyl whereas $\mathrm{C} 4$ products are formed either by recombination of methyl with $\mathrm{C} 3$ alkyl or two $\mathrm{C} 2$ alkyl radicals. At temperatures $\geq$ $1250{ }^{\circ} \mathrm{C}, 1,3$-butadiyne (diacetylene) is the major $\mathrm{C} 4$ product (Fig. 9). The gas phase formation of $\mathrm{C} 3$ and $\mathrm{C} 4$ coupling products is also in line with literature results. By

\section{References}

[1] A.P.E. York, T.-c. Xiao, M.L.H. Green and J.B. Claridge, Catal. Rev., 49 (2007) 511.

[2] J.H. Lunsford, Angew. Chem. Int. Ed. Engl., 34 (1995) 970.

[3] K. Tabata, Y. Teng, T. Takemoto and E. Suzuki, Catal. Rev., 44 (2002) 1.

[4] G.J. Hutchings, M.S. Scurrell and J.R. Woodhouse, Chem. Soc. Rev., 18 (1989) 251. combining isotope tracer experiments and numerical simulations, Mims et al. [49] traced the homogeneous coupling chemistry during methane oxidative coupling with focus on $\mathrm{C} 3$ and $\mathrm{C} 4$ formation. They found the higher hydrocarbon growth occurs through gas-phase radical reactions with little interference by the catalyst.

\section{Conclusion}

By combining in-situ measurements of $\mathrm{CH}_{3} \cdot$ radicals during methane catalytic partial oxidation on Pt with GC analysis of the reactor off-gases and temperature profile measurements of the reactor tube it was shown that the methane CPO proceeds via a heterogeneous-homogeneous mechanism. At $\mathrm{C} / \mathrm{O}=0.6$, ignition of surface chemistry is observed at around $600{ }^{\circ} \mathrm{C}$ leading to autothermal operation at $1000{ }^{\circ} \mathrm{C}$. From autothermal operation up to $\mathrm{T} \approx 1100^{\circ} \mathrm{C}$, oxygen conversion is incomplete and surface oxidation reactions to $\mathrm{CO}, \mathrm{H}_{2}, \mathrm{CO}_{2}$ and $\mathrm{H}_{2} \mathrm{O}$ dominate. No radicals are detected by threshold ionization indicating the absence of gas phase chemistry. If the temperature is increased above $1100^{\circ} \mathrm{C}$ an ignition is observed accompanied by complete oxygen conversion, detection of $\mathrm{CH}_{3}$. radicals, significant amounts of $\mathrm{C} 2$ coupling products and traces of $\mathrm{C} 3$ and $\mathrm{C} 4$ coupling products. This second ignition is attributed to exothermic gas phase radical chemistry. The measurements presented in this work provide the first experimental correlation between $\mathrm{CH}_{3}$. radical formation and formation of $\mathrm{C} 2$ products under high temperature and atmospheric pressure condition and confirm numerical predictions in the literature [23, 24]. In contrast to the methane oxidative coupling on strong basic oxides like $\mathrm{Li} / \mathrm{MgO}$, the role of $\mathrm{Pt}$ is not to generate $\mathrm{CH}_{3}$. radicals which desorb into the gas phase rather than to supply the necessary heat to initiate and sustain the radical forming gas phase chemistry.

\section{Acknowledgements}

The authors thank J. Ihmann for support during the construction phase of the high temperature reactor and A. Taha for setting up the pyrometer temperature measurements.
[5] R.J. Olsen, W.R. Williams, X. Song and L.D. Schmidt, Chem. Eng. Sci., 47 (1992) 2505.

[6] S. Chattopadhyay and G. Veser, AIChE J., 52 (2006) 2217.

[7] D.J. Discroll, K.D. Campbell and J.H. Lunsford, Adv. Catal., 35 (1987) 139.

[8] T.A. Garibyan and L.Y. Margolis, Catal. Rev.-Sci. Eng., 31 (1989) 335.

[9] D.A. Hickman and L.D. Schmidt, Science, 259 (1993) 343.

[10] D.T.P. Watson, J.J.W. Harris and D.A. King, J. Phys. Chem. B, 106 (2002) 3416 . 
[11] S.F. Rice, A.H. McDaniel, E.S. Hecht and A.J.J. Hardy, Ind. Eng. Chem. Res., 46 (2007) 1114.

[12] R. Horn, K.A. Williams, N.J. Degenstein, A.B. Larsen, D.D. Nogare, S.A. Tupy and L.D. Schmidt, Journal of Catalysis, 249 (2007).

[13] G.A. Somorjai and A.L. Marsh, Phil. Trans. R. Soc. A, 363 (2005) 879.

[14] A.L. Marsh, K.A. Becraft and G.A. Somorjai, J. Phys. Chem. B, 109 (2005) 13619.

[15] D.H. Fairbrother, X.D. Peng, M. Trenary and P.C. Stair, J. Chem. Soc., Faraday Trans., 91 (1995) 3619.

[16] D.H. Fairbrother, X.D. Peng, R. Viswanathan and P.C. Stair, Surf. Sci. Lett., 285 (1993).

[17] D.T.P. Watson, S. Titmuss and D.A. King, Surf. Sci., 505 (2002) 49.

[18] M. Valden, N. Xiang, J. Pere and M. Pessa, Appl. Surf. Sci., 99 (1996) 83

[19] O. Deutschmann and L.D. Schmidt, AIChE J., 44 (1998) 2465.

[20] K.H. Hofstad, T. Sperle, O.A. Rokstad and A. Holmen, Catal. Lett., 45 (1997) 97.

[21] R. Horn, K. Ihmann, J. Ihmann, F.C. Jentoft, M. Geske, A. Taha, K. Pelzer and R. Schlögl, Rev. Sci. Instrum., 77 (2006) 9.

[22] J.C. Mackie, Catal. Rev.-Sci. Eng., 33 (1991) 169

[23] R. Quiceno, O. Deutschmann, J. Warnatz and J. PerezRamırez, Catal. Today, 119 (2007) 311.

[24] R. Quiceno, J. Perez-Ramırez, J. Warnatz and O. Deutschmann, Appl. Catal. A, 303 (2006) 166.

[25] P. Berlowitz, D.J. Driscoll, J.H. Lunsford, J.B. Butt and H.H. Kung, Comb. Sci. Technol., 40 (1984) 317.

[26] Y. Feng, J. Niiranen and D. Gutman, J. Phys. Chem., 95 (1991) 6558 .

[27] M.B. Davis, M.D. Pawson, G. Veser and L.D. Schmidt, Combust. Flame, 123 (2000) 159.
[28] C.M. Marks and L.D. Schmidt, Chem. Phys. Lett., 178 (1991) 358.

[29] G.C. Eltenton, J. Chem. Phys., 15 (1947) 455.

[30] M. Sablier and T. Fujii, Chem. Rev., 102 (2002) 2855.

[31] G. Wannier, Phys. Rev., 90 (1953) 817.

[32] R.E. Winters, J.H. Collins and W.L. Courchene, J. Chem. Phys., 45 (1966) 1931.

[33] F.P. Lossing and G.P. Semeluk, Can. J. Chem, 48 (1970) 955.

[34] P. Plessis, P. Marmet and R. Dutil, J. Phys. B, 16 (1983) 1283.

[35] P. Plessis and P. Marment, Can. J. Chem, 65 (1987) 1424.

[36] H. Singh, J.W. Coburn and D.B. Gravesa, J. Vac. Sci. Technol. A, 18 (2000).

[37] http://webbook.nist.gov/chemistry.

[38]

http://physics.nist.gov/PhysRefData/Ionization/molTable.html.

[39 http://discoverysciences.com/chromdb/default.aspx.

[40] P. Aghalayam, Y.K. Park, N. Fernandes, V. Papavassiliou, A.B. Mhadeshwar and D.G. Vlachos, J. Catal., 213 (2003) 23.

[41] C. Gueret, M. Daroux and F. Billaud, Chem. Eng. Sci., 52 (1997) 815.

[42] O. Olsvik, O.A. Rockstad and A. Holmen, Chem. Eng. Technol., 18 (1995) 349.

[43] K.L. Hohn, P.M. Witt, M.B. Davis and L.D. Schmidt, Catal. Lett., 54 (1998) 113.

[44] T. Ito, J.-X. Wang, C.-H. Lin and J.H. Lunsford, J. Am. Chem. Soc., 107 (1985) 5062.

[45] K.D. Campbell, E. Morales and J.H. Lunsford, J. Am. Chem. Soc., 109 (1987) 7900.

[46] S.N. Foner and R.L. Hudson, J. Chem. Phys., 25 (1956).

[47] S.S. Bharadwaj and L.D. Schmidt, Fuel Proc. Technol., 42 (1995) 109.

[48] F. Paneth and W. Hofeditz, Ber., 62B (1929) 1335.

[49] C.A. Mims, R. Mauti, A.M. Dean and K.D. Rose, J. Phys. Chem., 98 (1994) 13357. 